\title{
Vegetación, clima y relieve: Valoración del geopaisaje de Choccocconiri
}

\author{
Poma Porras Orlando Alan ${ }^{\mathrm{a}}$, Roman Medrano Maria Alejandra ${ }^{\mathrm{a}}$, Zegarra López Zabdi Magdalena ${ }^{\mathrm{a}}$, \\ Madrigal Perez Glen Bryan ${ }^{\mathrm{b}}$
}

${ }^{a}$ EP. Ingeniería Ambiental, Facultad de Ingeniería y Arquitectura, Universidad Peruana Unión, , Centro de Recursos en Geociencia - Lima

${ }^{b}$ EP. Ingeniería Ambiental, Facultad de Ingeniería y Arquitectura Universidad Peruana Unión, Centro de Recursos en Geociencia - Sede Juliaca

\section{Resumen}

El objetivo de este trabajo es la identificación de la vegetación, características del clima y relieve existente en la comunidad de Choccocconiri. El trabajo en campo se realizó con recorridos en sectores diferentes por 5 días, capturando lo encontrado con la cámara fotográfica, el dron Phanton 4 pro permitió captar imágenes panorámicas con 50 metros de altura promedio, para complementar esta información se hizo uso del Mapa de Cobertura Vegetal de Perú y el Índice de Vegetación de Diferencia Normalizada (NDVI), el NDVI se realizó a través de técnicas de percepción remota utilizando datos satelitales multiesprectales correspondientes al satélite LANDSAT 8. La altitud y pendiente, se obtuvieron a partir de un Modelo Digital de Elevación (MDE) trabajados en el programa Arcgis 10.2; los datos climáticos se obtuvieron del Mapa Climático del Perú. Como resultado se registraron 70 especies vegetales entre líquenes, musgos, algas, gramíneas, árboles y un hongo en tiempo de reproducción; entre estas especies algunas plantas acuáticas y líquenes resultan bioindicadores de la buena calidad ambiental que hay en Choccocconiri. Los datos de campo son corroborados con los datos del Mapa de cobertura vegetal y el NDVI. En conclusión, las variables climáticas (temperatura media de $7^{\circ} \mathrm{C}$ y precipitación media anual de $700 \mathrm{~mm}$ ), la altitud $(3900-4200 \mathrm{msnm}$ ), pendiente (suave a moderada) y todos los datos analizados se relacionan con el tipo de vegetación que existe en Choccocconiri. Estos elementos encontrados nos dan un soporte para tener una valoración positiva del geopaisaje de Choccocconiri.

Palabras clave: Vegetación; clima; relieve; geopaisaje; Choccocconiri

\section{Abstract}

The objective of this work is the identification of the vegetation, characteristics of the climate and reliev existing in the community of Choccocconiri. The field work was carried out with tours in different sectors for 5 days, capturing what was found with the camera, the dron Phanton 4 pro allowed to capture panoramic images with 50 meters of average height, to complement this information was made use of the Map of Coverage Vegetable of Peru and the Normalized Difference Vegetable Index (NDVI), the NDVI was performed using remote sensing techniques using multiscale satellite data corresponding to the LANDSAT 8 satellite. The altitude and slope were obtained from a Digital Model of Elevation (MDE) worked in the program Arcgis 10.2; The climatic data were obtained from the Climate Map of Peru. As a result, 70 plant species were recorded among lichens, mosses, algae, grasses, trees and a fungus at time of reproduction; Among these species some aquatic plants and lichens are bioindicators of the good environmental quality that exists in Choccocconiri. The field data are corrobobrados with the data of the Map of vegetal cover and the NDVI. In conclusion, the climatic variables (average temperature of $7^{\circ} \mathrm{C}$ and average annual precipitation of $700 \mathrm{~mm}$ ), altitude (3900-4200 msnm), slope (mild to moderate) and all data analyzed are related to the type of vegetation that exists In Choccocconiri. These elements found give us a support to have a positive valuation of the geopaisaje of Choccocconiri.

Keywords: Vegetation; weather; relief; Geopasaje; Choccocconiri 


\section{Introducción}

Las plantas son muy importantes para el medio ambiente y el ser humano, esta importancia radica tanto en el aspecto ecológico como económico; más aún, las plantas, según su distribución y abundancia, caracterizan el paisaje, distinguiéndose los desiertos, la sabana, la puna, los bosques húmedos, los bosques secos, etc. (Brack \& Mendiola, 2000). Muchas veces las investigaciones suelen ser costosas al centrarse en un solo aspecto puede ser suelo, o aire claro que los resultados son buenos, pero al identificar especies de flora, y conocer un poco su comportamiento se puede entender no solo a estas, también su entorno actual, incluso algo del paleoambiente. Para Galan de Mera, Rosa, \& Cáceres, (2002) la vegetación de América del Sur alberga una gran diversidad y la zona del altiplano de Perú estudiada en este artículo no es la excepción.

El área de estudio de la investigación se encuentran dentro de la cordillera de los andes, el cual presenta una gran variedad de vegetación a lo largo de sus 7000 km (Galán de Mera, Cáceres, \& Gonzales, 2003), no obstante, para fines del presente artículo, se localiza en la región fitogeográfica de la Puna y los altos andes (distribuido desde Cajamarca hasta Puno), esta región comprende formaciones de gramíneas, los bosques de quinuales, los rodales de ccara o titanca, los matorrales altoandinos, los tolares, la estepa de Tetraglochin, las roquedias con vegetación mixta, los semidesiertos altoandinos, las formaciones de plantas almohadilladas, las turberas o bofedales, los totorales, y la Puna de cactáceas (Brack \& Mendiola, 2000).

La presencia o ausencia de plantas se debe siempre al entorno en el que se encuentran, ya que, si las condiciones son aptas para la especie, se desarrollará con naturalidad de lo contrario no. Así que conocer las plantas presentes en un lugar y ciertos comportamientos pueden ser de gran ayuda para entender un espacio natural y poder tomar medidas preventivas o acciones conservacionistas según indique el estado de estas. Es por eso que esta investigación busca ver la relación entre el clima, el relieve y los vegetales presentes en la comunidad de Choccocconiri, se puede conocer mucho sobre el estado de los suelos, de la calidad de aire y del agua, tan solo con la observación de especies, como por ejemplo Lijteroff, Lima y Prieri en el 2009 menciona que durante los últimos tiempos, numerosos estudios han utilizado líquenes epifitos para estimar los niveles de contaminación atmosférica creada principalmente por el dióxido de azufre; pero no solo es una especie si no que "se conocen numerosos organismos que pueden ser utilizados como bioindicadores; se incluyen especies de plantas vasculares, briófitas, algas, líquenes, hongos, animales invertebrados y animales vertebrados" (Lijteroff et al., 2009). También la presencia de helechos puede ser de gran interés, conocidos también como pteridófitos son plantas que no producen flores ni semillas, y su reproducción posee caracteres muy primitivos. Por ello se les considera dentro de las Criptógamas o vegetales “inferiores”(Vázquez \& Arregui, 2006). Resultan muy interesantes, en su comportamiento.

Con respecto al clima, este tiene un papel muy fundamental en la distribución de la vegetación y esto fue puesto de manifiesto desde hace ya mucho tiempo por TEOFRASTO en el siglo III a.c. (Hort, 1916), por ello el conocimiento del clima en un determinado área puede darnos información acerca del tipo de vegetación 
que aparece en la misma (Gavilán, 1994), de manera que en las últimas décadas se han incrementado las investigaciones en el tema cobertura vegetal - clima (Rodriguez, Pabón, Bernal y Martínez, 2010). Además del clima, existen naturalmente ciertos factores como son el relieve, topografía, tipos de suelo, que también influyen de forma muy importante sobre la vegetación (Gavilán, 1994).

El objetivo del presente trabajo es identificar las especies vegetales de la Comunidad de Choccocconiri, Distrito de Juli, provincia de Chucuito, del Departamento de Puno y ver qué relación tienen con el clima y el relieve del lugar, para lo cual se recopilo información en campo y en la bibliografía existente.

\section{1. Área de Investigación}

La investigación se realizó en la Comunidad de Choccocconiri ubicado en las coordenadas UTM 19K 437361 O, $8195745 \mathrm{~S}$ a una altura de $3922 \mathrm{msnm}$. Choccocconiri es una comunidad que está dentro del Distrito de Juli (provincia de Chucuito, departamento de Puno, en el sudeste de Perú) (Figura 1).

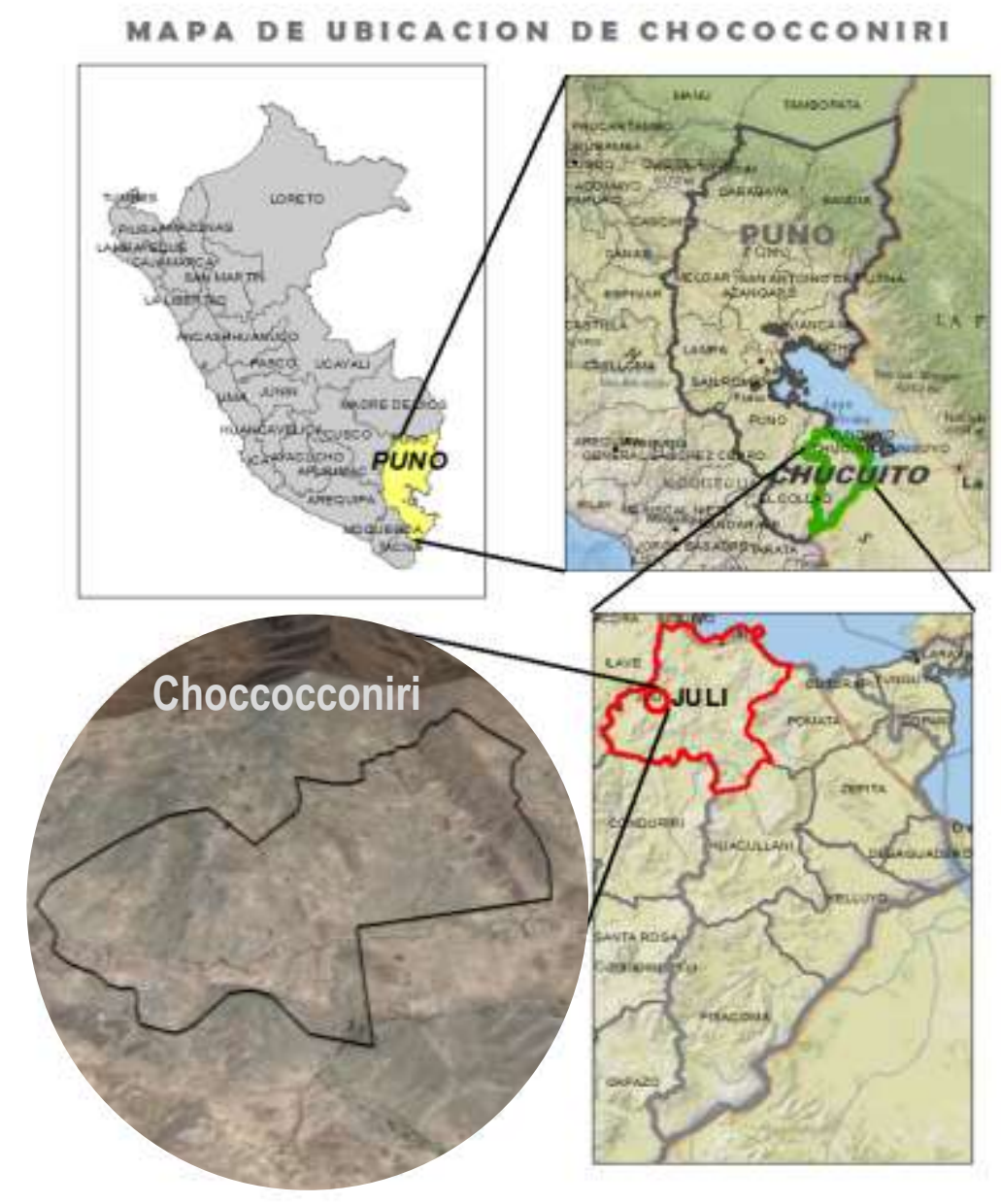

Figura 1. Mapa de ubicación de Choccocconiri Elaborado por: Madrigal G. (2017) 


\section{Materiales y métodos}

\subsection{Materiales utilizados}

Se hizo uso de diferentes materiales para los recorridos y recolección de información en campo y diferentes instrumentos fuera de el para la observación del territorio.

\subsubsection{En la comunidad de Choccocconiri:}

Cámara fotográfica, Dron Phanto 4 pro, Libreta de apuntes, GPS Garmin Etrex 10

\subsubsection{En el procesamiento de la información}

Imágenes de Google Earth Pro, imágenes del satelite Landsat 8, curvas de nivel descargados de la página web del Instituto Geográfico Nacional del Perú, Mapa climático del Perú SENAMHI, El software Arcgis 10.2

\subsection{Metodología empleada}

El método empleado para esta investigación implica dos secciones principales, la de observación en campo e identificación de especies, y el análisis de su relación con el clima y el relieve a través de bibliografía e instrumentos SIG. La investigación se proyectó en gran medida sobre el paisaje, del que interesaron tanto sus características físicas (clima, relieve) y naturales (vegetación). Se realizó el estudio de la vegetación, clima y relieve en zonas comprendidas dentro de la comunidad de Chococoniri, cuya área es de $17721 \mathrm{~m}^{2}$ (figura 2).

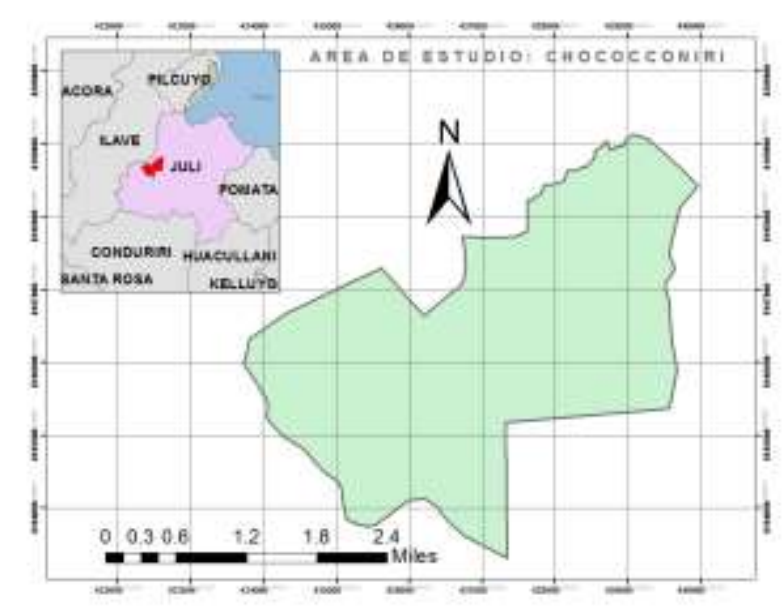

Figura 2. Mapa del área de studio Elaborado por: Madrigal G. (2017) 
El estudio de la vegetación se realizó en campo, estos datos fueron recopilados entre los días 10 al 14 de Julio del 2017. La metodología consistió en identificar los tipos de especies vegetales predominantes en el área de estudio, para lo cual se realizo el recorrido en campo por sectores, el sector de Chocco, el sector Cconiri, tambien la zona plana abundante en humedales y la zona centro Joj'sani (figura 3). En el recorrido se tomaron muestras y fotografías para identificarlas; Los pobladores de la comunidad conocedores de las especies y algunas propiedaes, nos condujeron a los potenciales lugares con gran variedad de especies vegetales.

Por otro lado, para complementar el trabajo de campo en lo referente a la vegetación, se utilizó el Mapa de cobertura vegetal y el Índice de Vegetación de Diferencia Normalizada (NDVI), el NDVI se realizó a través de técnicas de percepción remota utilizando datos satelitales multiesprectales correspondientes al satélite Landsat 8 sobre el área de estudio.

El NDVI es un buen estimador de la vegetación, es usado universalmente y ha resultado el índice verde más consistente para monitoreo de vegetación en los ambientes y situaciones más diversos (Aguilar, Galindo, Fortanelli, \& Contreras, 2010). Para el cálculo de este índice de vegetación se hizo uso del programa SIG Arcgis 10.2. El NDVI es una relación normalizada de la reflectancia espectral (NIR) y rojo, dada por la siguiente relación: (NIR-rojo) / (NIR+rojo) (Hutchinson, Jacquin, Hutchinson, \& Verbesselt, 2015) en las imágenes Landsat 8 la banda 5 corresponde a la reflectancia espectral (NIR) y la banda 4 al rojo. Los valores crudos de NDVI son números reales fraccionarios y adimensionales que oscilan entre $-1 \mathrm{y}+1$ siendo los valores más cercanos a +1 la vegetación más vigorosa y los valores negativos corresponden principalmente a las nubes, el agua y la nieve (Millano \& Paredes, 2017).

El relieve que es de fundamental importancia para la presencia de diferentes especies vegetales se observó a través de imágenes de google earth y las imágenes del Dron Phanton 4Pro utilizado en el estudio de campo. Además, el relieve se obtuvo a partir de un modelo digital de elevaciones (MDE), el MDE se generó con el programa Arcgis versión 10.2 a partir de curvas de nivel descargados de la página web del Instituto Geográfico Nacional del Perú.

Para obtener información del clima se utilizaron datos del Servicio Nacional de Meteorología e Hidrología del Perú (SENAMHI) integrados en el "Mapa Climático del Perú" que está basado en la clasificación de climas de Werren Thornthwaite. 


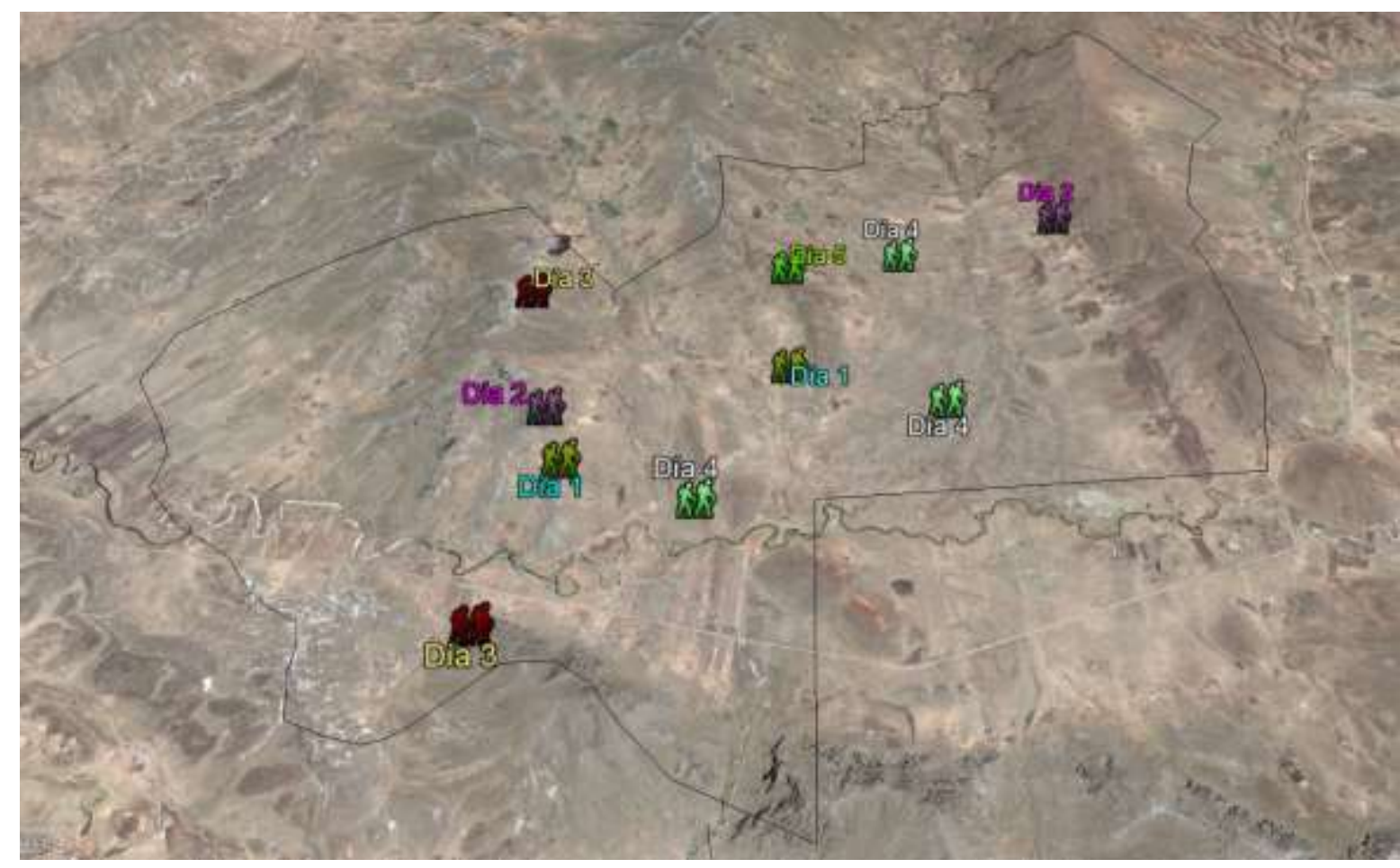

Figura 3. Sectores recorridos durante 5 días en la comunidad e Chcoccocconiri Elaborado por: Roman M. (2017)

\section{Resultados}

En general las especies identificadas presentan directa relación al clima y el relieve del lugar y entre ellas se encontraron bioindicadores de la buena calidad ambiental de la comunidad.

\subsection{Vegetación}

Choccocconiri presenta una vegetación en buen estado de conservación, pues las actividades antrópicas son mínimas (ganadería y pastoreo); además la vegetación identificada es característica de esta zona (Puna), lo que indica que aun no hay tanta alteración ni cambios en esa zona.

En total se registraron 70 especies, en las diferentes zonas de toda el área de estudio $\left(17721 \mathrm{~m}^{2}\right)$. Entre ellas líquenes, musgos, algas, gramíneas, árboles y un hongo en tiempo de reproducción.

\subsubsection{Líquenes}

Los líquenes en su totalidad de observaciones fueron litófitos, todos se establecen y foman grandes colinias sobre las rocas, los líquenes según se observó son agentes en la erosión de las rocas ya que permanecer pegados a estas debilitan las areniscas y las terminan fragmentando. Con latitud $16^{\circ} 18^{\prime} 17.41^{\prime \prime S}$ y longitud $69^{\circ} 36^{\prime} 11.52^{\prime \prime O}$ se registró un punto donde se aprecia un espacio aproximado de 25 metros cuadrados con sinecias de diferentes especies de plantas inferiores resaltando los líquenes en grandes cantidades. 


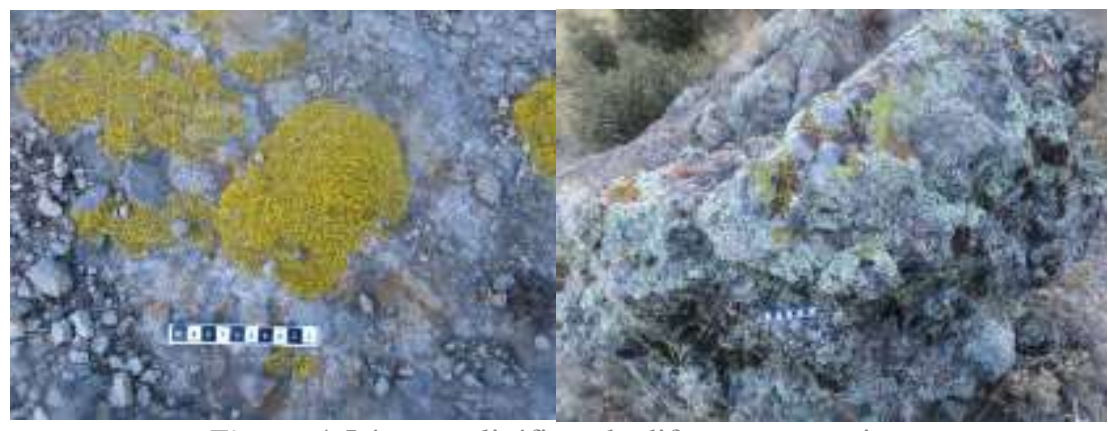

Figura 4. Líquenes litófitos de diferentes especies.

Fotografias: Roman M. (2017)

\subsubsection{Musgos}

Los musgos fueron avistados en casi todas las zonas siendo más notables en la zona centro Joj'sani, también se observó diferentes ambientes en los que se desarrollan. Encontramos en su mayoría litófitos (crecen sobre las rocas), y algunos muy cercanos a fuentes de agua que presentan colores más intensos como el musgo de la izquierda de la Figura 5.

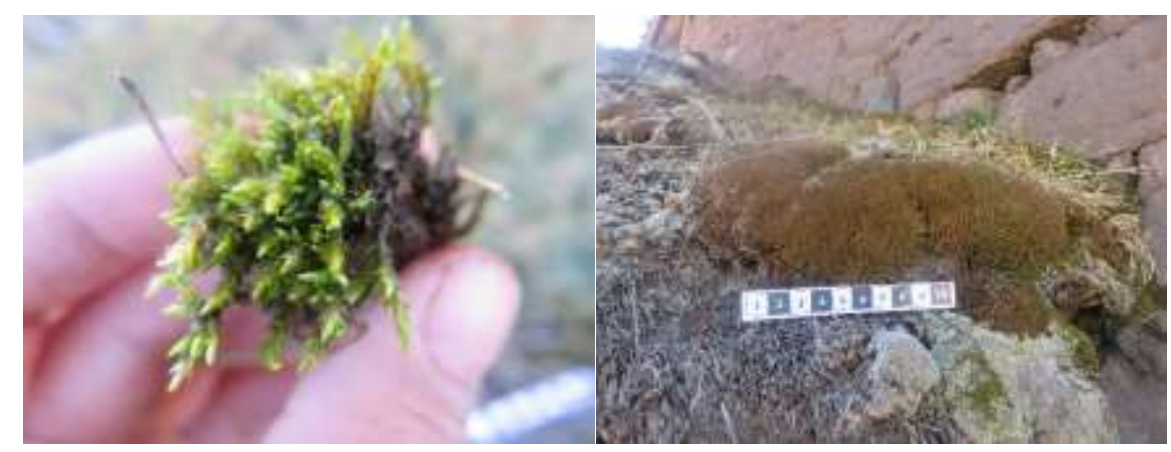

Figura 5. Musgos de la zona Joj'sani

\subsubsection{Plantas acuáticas}

Fotografias: Roman M. (2017)

En la zona abundan los manantiales y humedales y esto da lugar a una gran variedad de plantas acuáticas observándose las más abundantes en la Figura 6, con latitud 16 18'58.90"S y longitud $69^{\circ} 35^{\prime} 11.26$ "O se registró una especie, según indican las personas de la comunidad solo se encuentra en lugares donde el agua es limpia y efectivamente durante los 5 días solo se presenció esta especie en los manantiales donde el agua era cristalina. 


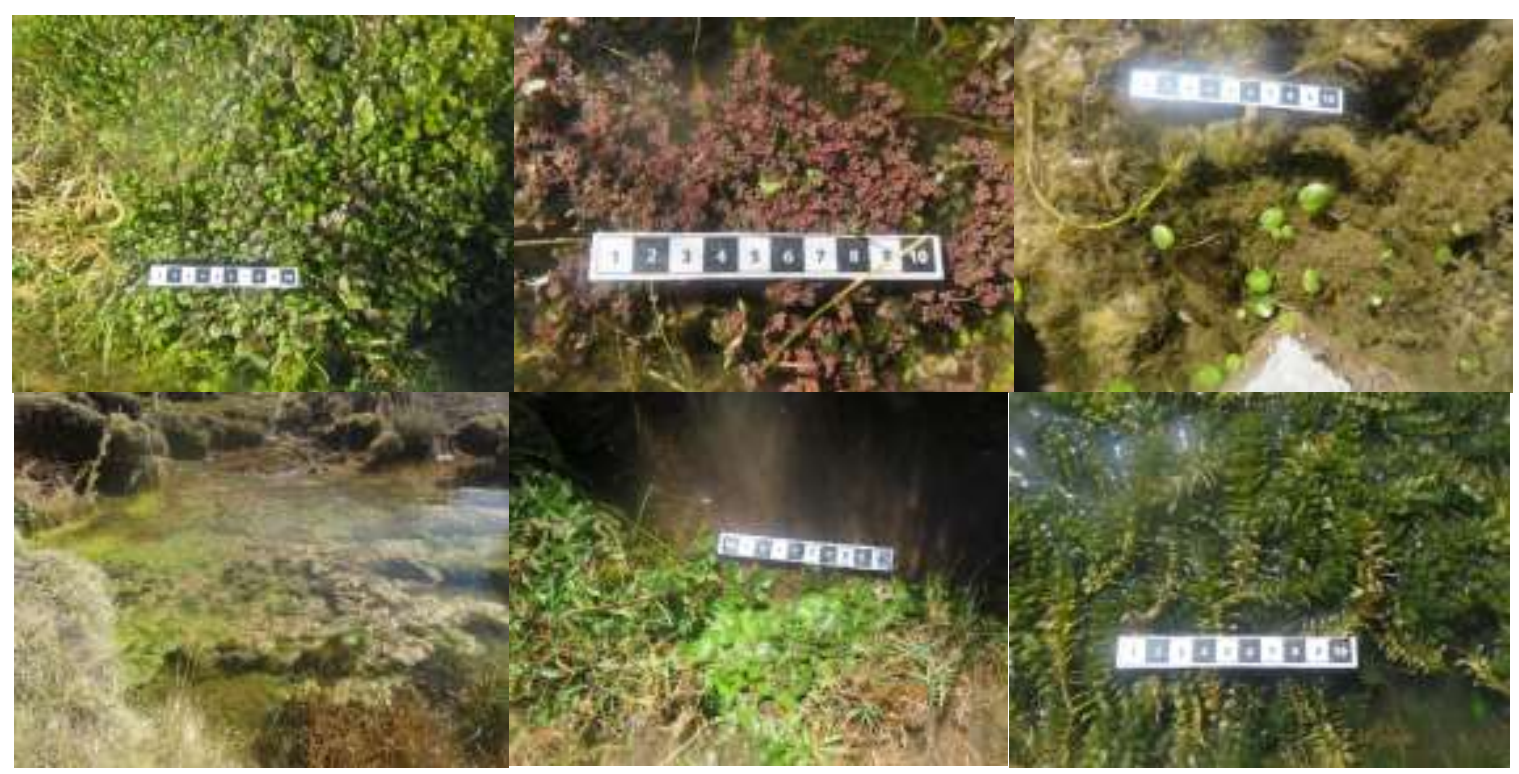

Figura 6. Plantas acuáticas de Choccocconiri Fotografias: Roman M. (2017)

\subsubsection{Plantas terrestres en tiempo de floración}

Fueron un promedio de 15 especies que se encontraron en floración, las especies en su mayoría con flores de tonalidades entre naranja amarillo y blanco, en el caso de la comúnmente llamada k'ela la flor es lila azulado, una de las flores más vistosas fue la flor naranja de la ortiga que se encontraba en las partes más altas a unos 4141msnm. Una especie llamada sik’i por la comunidad tiene una característica especial, cuando florea no se encuentra ni una hoja verde o en buen estado, por lo contrario cuando las hojas están en su mejor situación no hay flores, es muy parecida a la comúnmente llamada diente de león en la Figura 7 en la parte central superior se encuentra la última y en la parte central inferior un ejemplar de sik'i en floración, se encontró un extenso espacio con muchas de ellas a una latitud de 16²18'30.35"S y longitud $69^{\circ} 36^{\prime} 7.17$ "O.

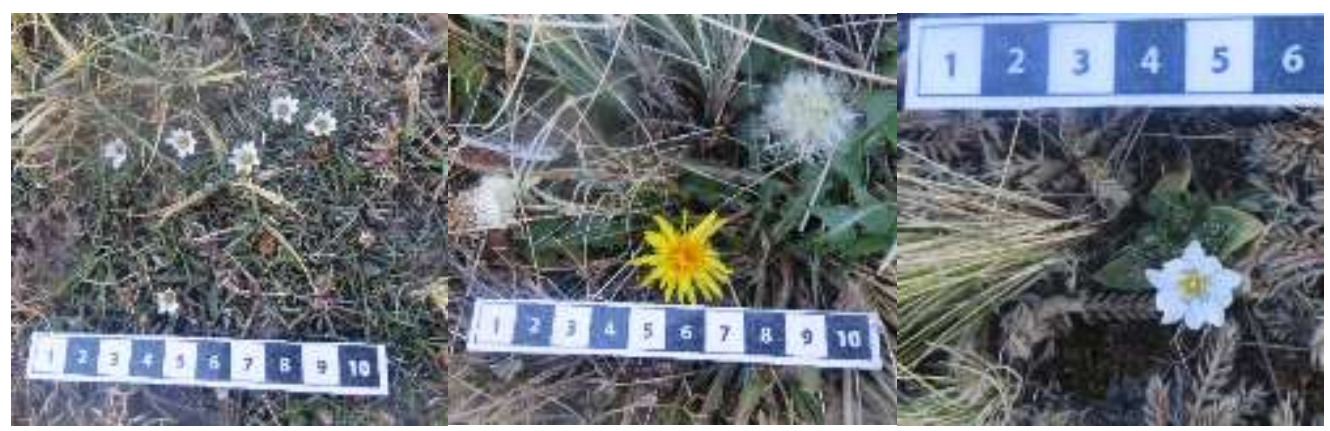




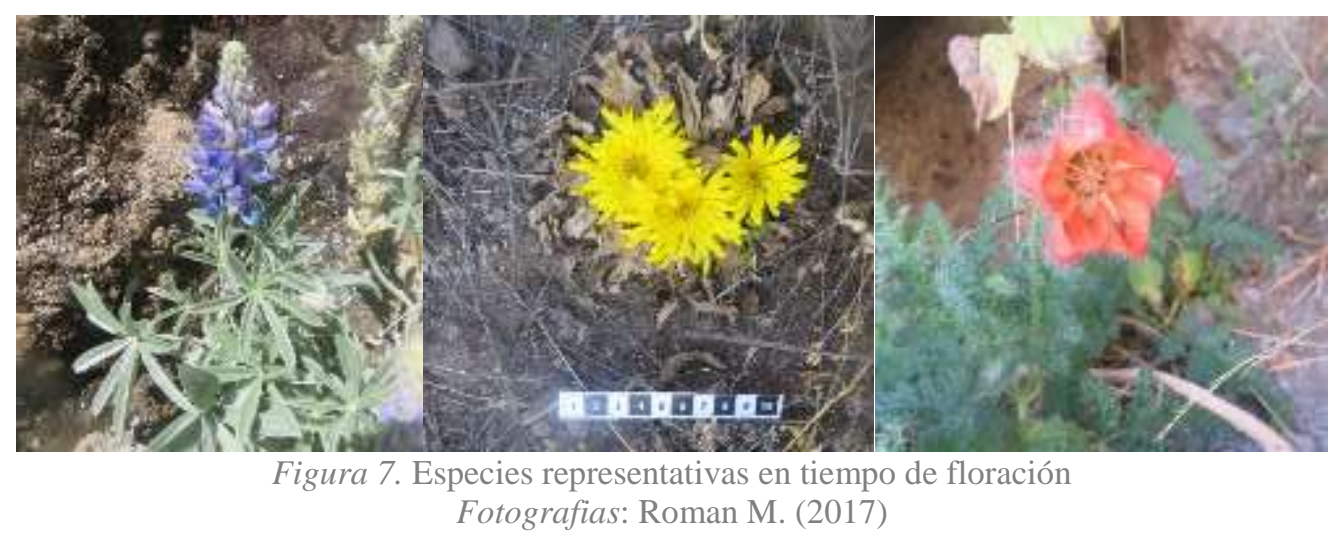

\subsubsection{Gramíneas}

Lo más abundante y perceptible desde las imágenes satelitales y en los recorridos fueron las gramíneas, aun cuando en los campos abiertos y planos no se distinguen muchas diferencias existe alta variedad de estas especies en Choccocconiri. Algunas de ellas son la paja brava, la chilligua, ichu, ch'quiji que es el alimento preferido de las alpahacas pasto pequeño es el tercero de la siguiente figura.

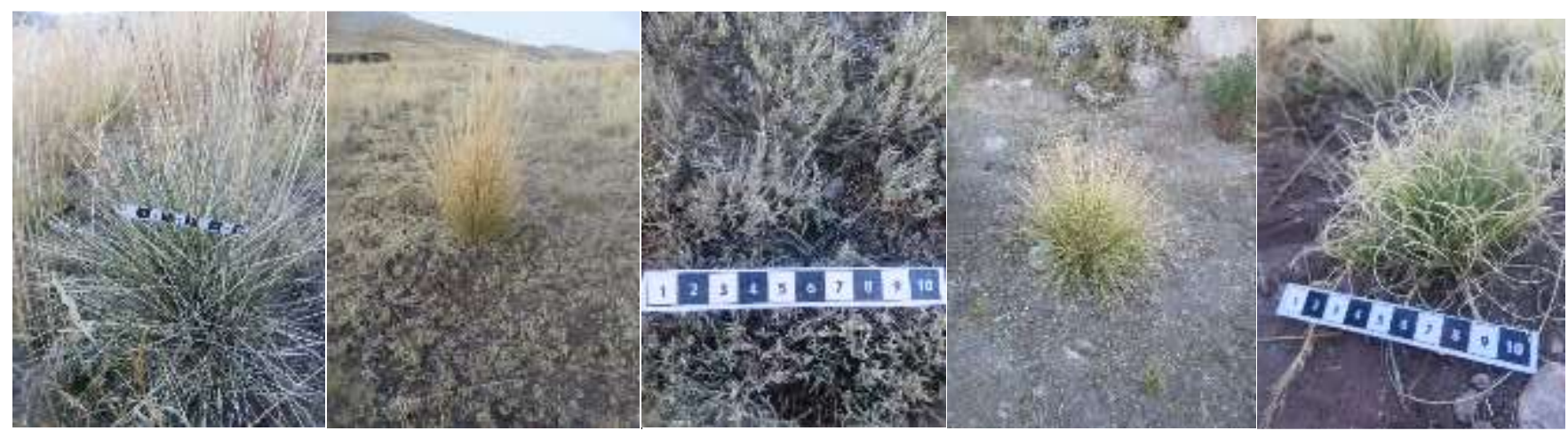

Figura 8. Gramíneas mas abundantes en todo el territorio de la comunidad de Choccocconiri.

Fotografias: Roman M. (2017)

\subsubsection{Cactus}

Los cactus encontrados son de gran utilidad para los agricultores como es el caso del sancayo, que según afecte la helada a este indica el efecto en los cultivos siguientes, el primer día se encontró un cactus especial y muy raro de avistar el segundo de la figura 9, que por las pelusas blancas que lo cubren parece inofensivo sin embargo el dolor que pueden provocar es mayor al de las espinas en forma de alfiler del resto.

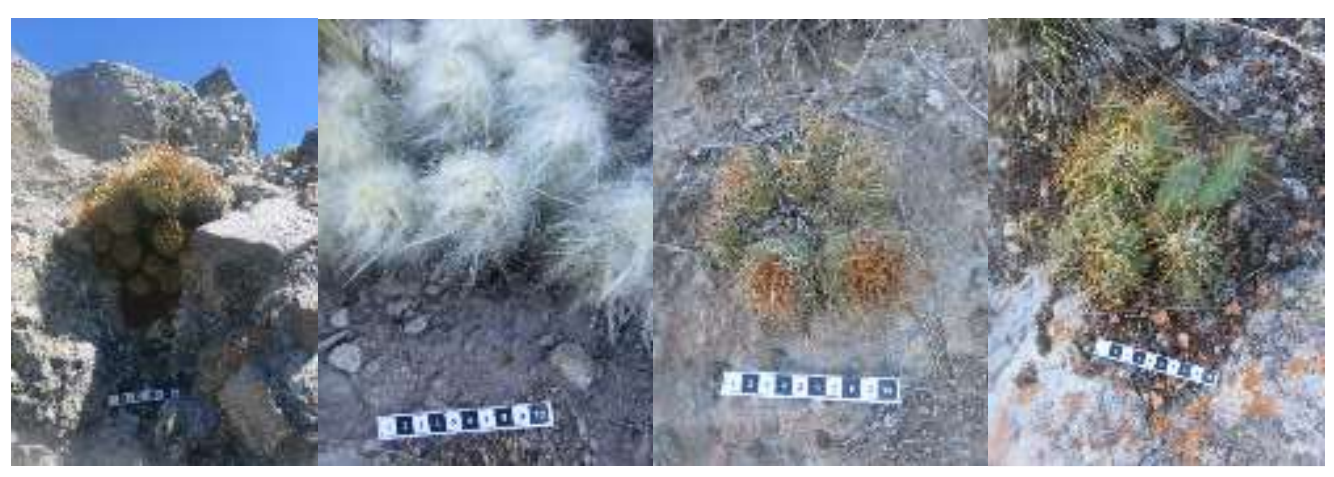


Figura 9. Diferentes cactus encontrados en las zonas altas del territorio. Fotografias: Roman M. (2017)

\subsubsection{Tres especies que se desarrollan juntas en zona húmeda}

En los diferentes recorridos por la zona se ha podido observar unas pequeñas especies que crecen muy juntas, esto llamo la atención y una característica similar que tiene es la degradación de color en sus hojas que va de rojo a verde en las tres especies. Se observaron en la zona de Isca Choco, En Joj'sani, y en las zonas más húmedas de la parte plana de la comunidad.

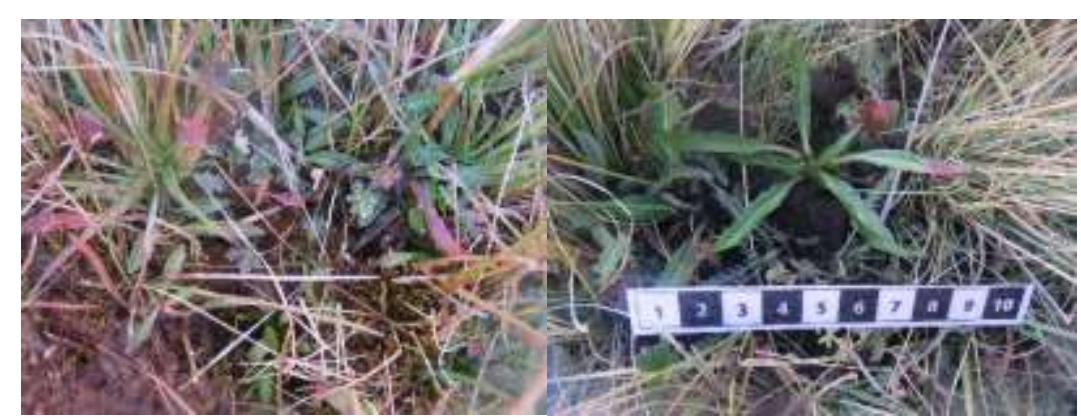

Figura 10. Asociación de plantas en el humedal Fotografias: Roman M. (2017)

La pigmentación de estas es similar y se relaciona con el comportamiento de otras especies de frio ya que el pigmento rojo permite resistencia al frío.

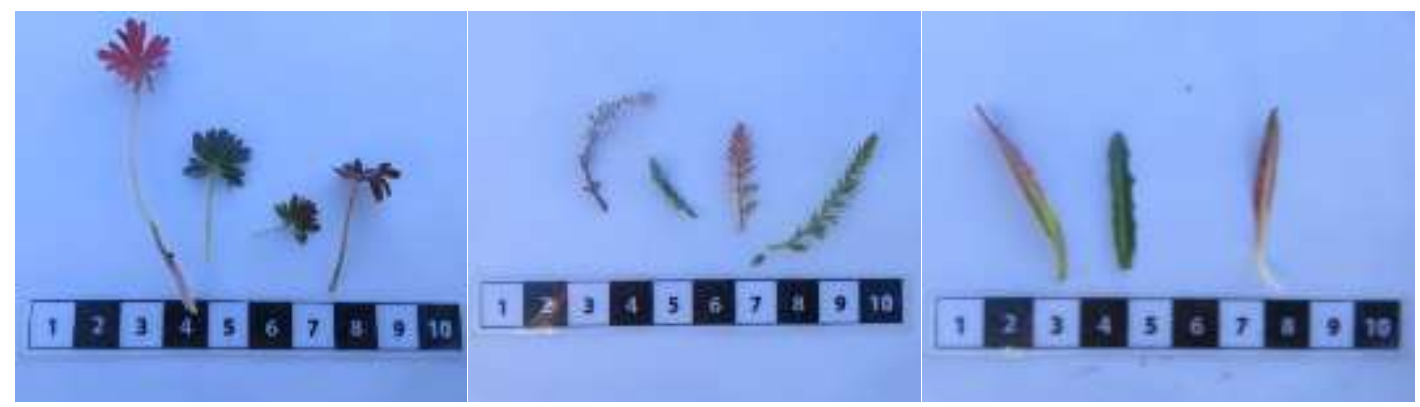

Figura 11. Vista de las tres especies, coloración de rojo a verde Fotografias: Roman M. (2017)

\subsubsection{Hongo}

El único hongo encontrado durante los cinco días fue este de casi unos $10 \mathrm{~cm}$ en tiempo de reproducción, en la zona de Joj’sani, con latitud 16²18'58.90"S y longitud 69³5'11.26"O. 


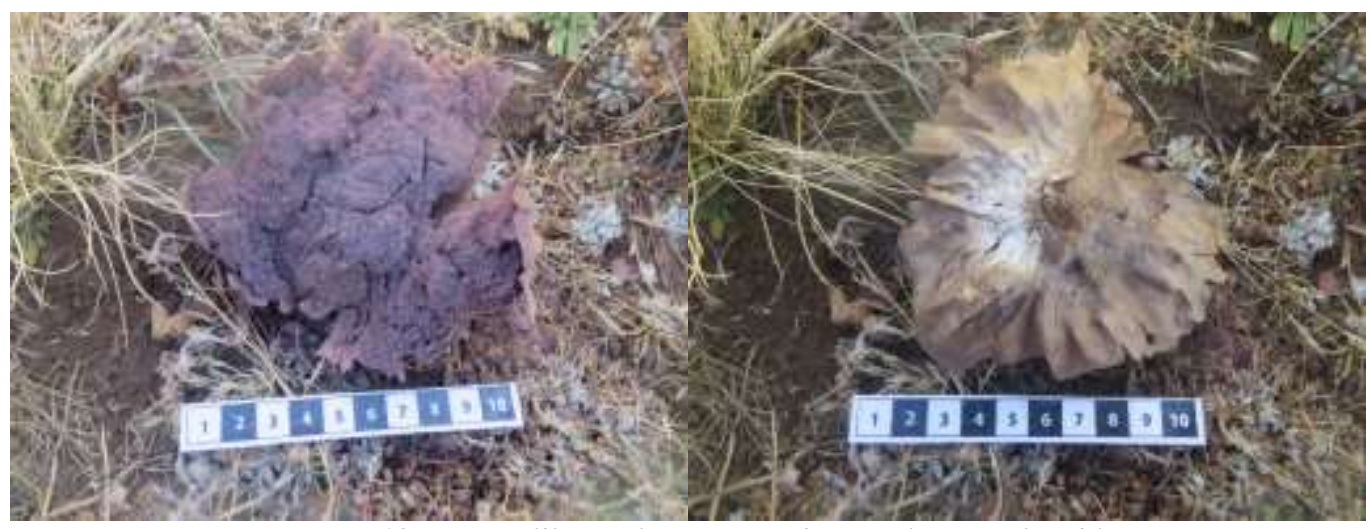

Fiugura 12. Hongo liberando esporas, tiempo de reproducción

Fotografias: Roman M. (2017)

\subsubsection{Especies cultivadas en la comunidad}

La comunidad básicamente se sustenta a través de la ganadería y agricultura siendo las principales especies cultivadas la quinua, la kañigua, la cebada, y diversos forrajes para su ganado.

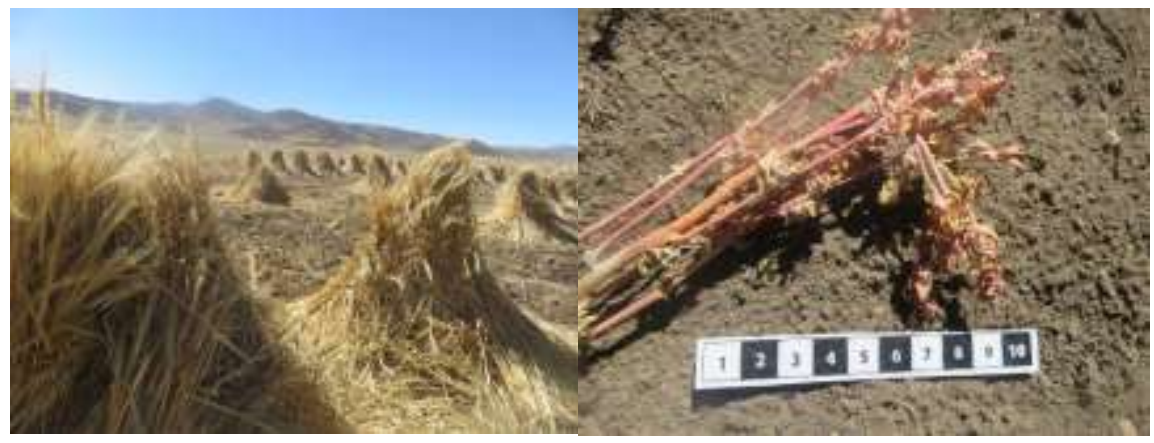

Figura 13. Forraje acomodado, y kañigua blanca cosechada. Fotografias: Roman M. (2017)

\subsection{Mapa de cobertura Vegetal e Índice de Vegetación de Diferencia Normalizada (NDVI)}

En los siguientes mapas, tanto en el mapa de Cobertura vegetal del Perú y el mapa NDVI, podemos ver la distribución de las diferentes especies existentes en Choccocconiri.

El mapa de Cobertura Vegetal (figura 14) nos muestra que las coberturas vegetales predominantes en Choccocconiri son: pajonal andino, bofedal y agricultura andina, esta última es considerara una unidad antrópica de cobertura vegetal (MINAM, 2015). Las superficies que ocupan el pajonal andino, bofedal, y agricultura andina son $55.18 \%, 1.01 \%$ y $43.82 \%$ respectivamente. 


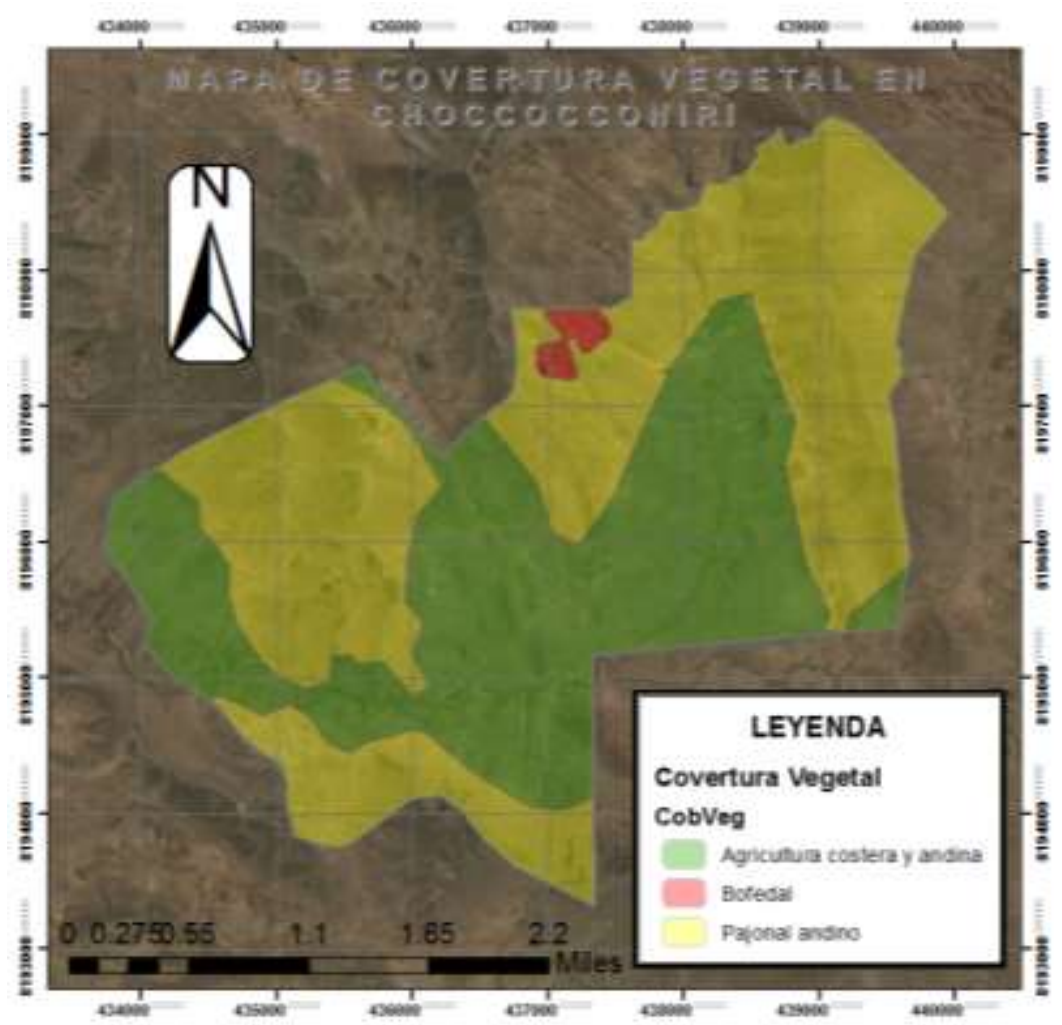

Figura 14. Mapa de cobertura vegetal Elaborado por: Madrigal G. (2017)

En la figura 15 se puede visualizar el resultado del cálculo del NDVI, el cual presenta valores que oscilan entre 0.0044 a 0.3047 para cada pixel de la imagen, la media está en 0.14 (ver histograma, figura 16).

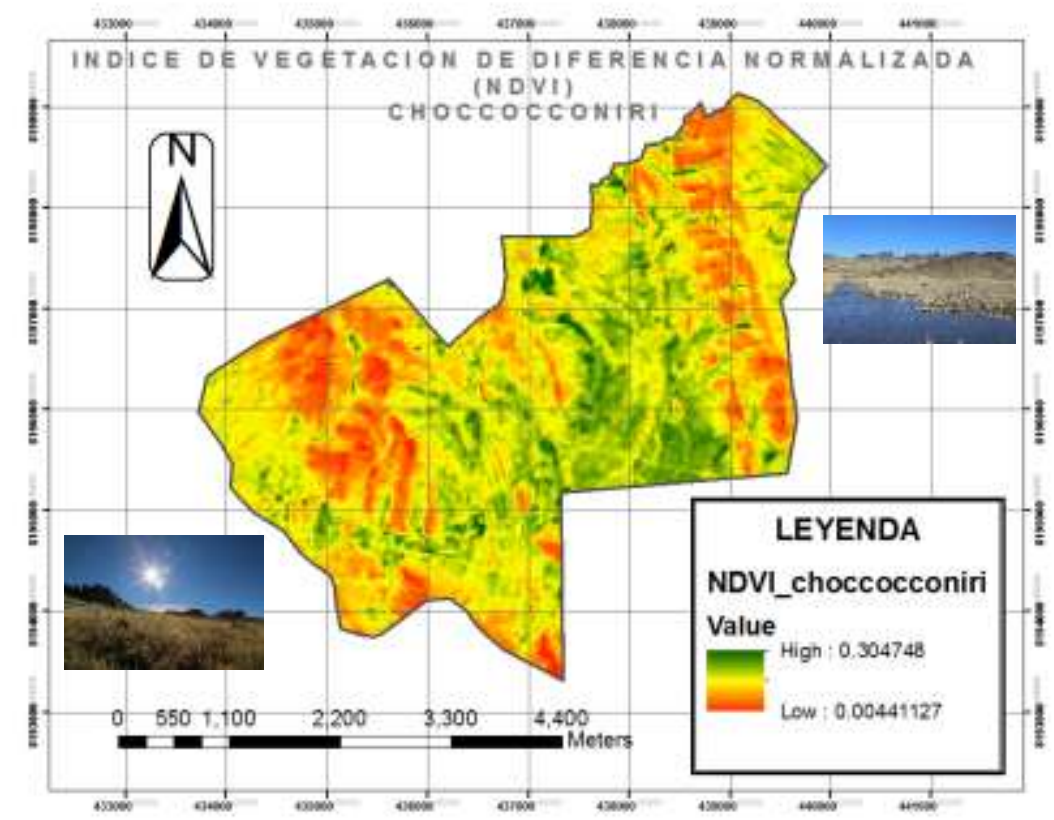

Figura 15. Índice de Vegetación de Diferencia Normalizada (NDVI) Elaborado por: Madrigal G. (2017) 


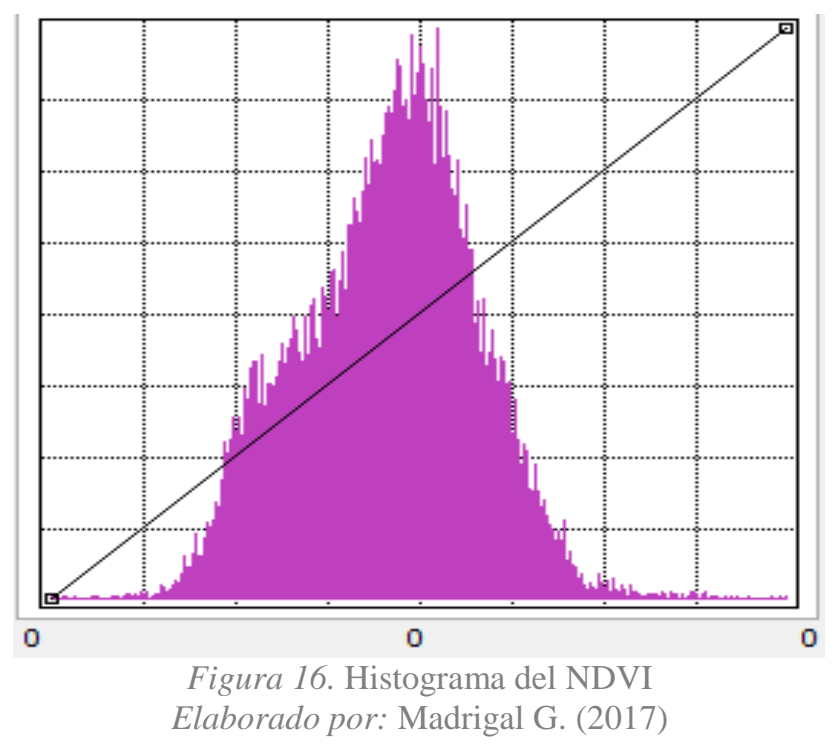

La vegetación más saludable se muestra en un verde oscuro esto es así porque esta vegetación se encuentra cerca a fuentes de agua, esta vegetación está conformada principalmente por pastos o pajonales saludables (verdes) y algunos arbustos; los colores amarillos muestran una vegetación pobre (prados, pastos, yermas de rocas, etc); los colores que son cercanos al rojo representan principalmente rocas y suelos desnudos o sin vegetación. En definitiva, debido a que la media es 0.14 la vegetación dominante está conformada por herbazales.

\subsection{Clima}

Según el mapa climático, Choccocconiri presenta generalmente un clima lluvioso semifrigido (de Tundra), este clima se caracteriza por presentar precipitaciones anuales en promedio de $700 \mathrm{~mm}$, temperaturas medias anuales de $7^{\circ} \mathrm{C}$ y nieves perpetuas en alta montaña. Presenta veranos lluviosos e inviernos secos con heladas moderadas. También presenta un clima frio Boreal (de los valles Mesoandinos), este clima se presenta en áreas muy pequeñas, al Nornordeste y al Suroeste de Choccocconiri (en los límites de la comunidad), con características similares al clima lluvioso semifrigido con la única diferencia de que su temperatura media es de $12^{\circ} \mathrm{C}$ (SENAMHI, s.f.) 


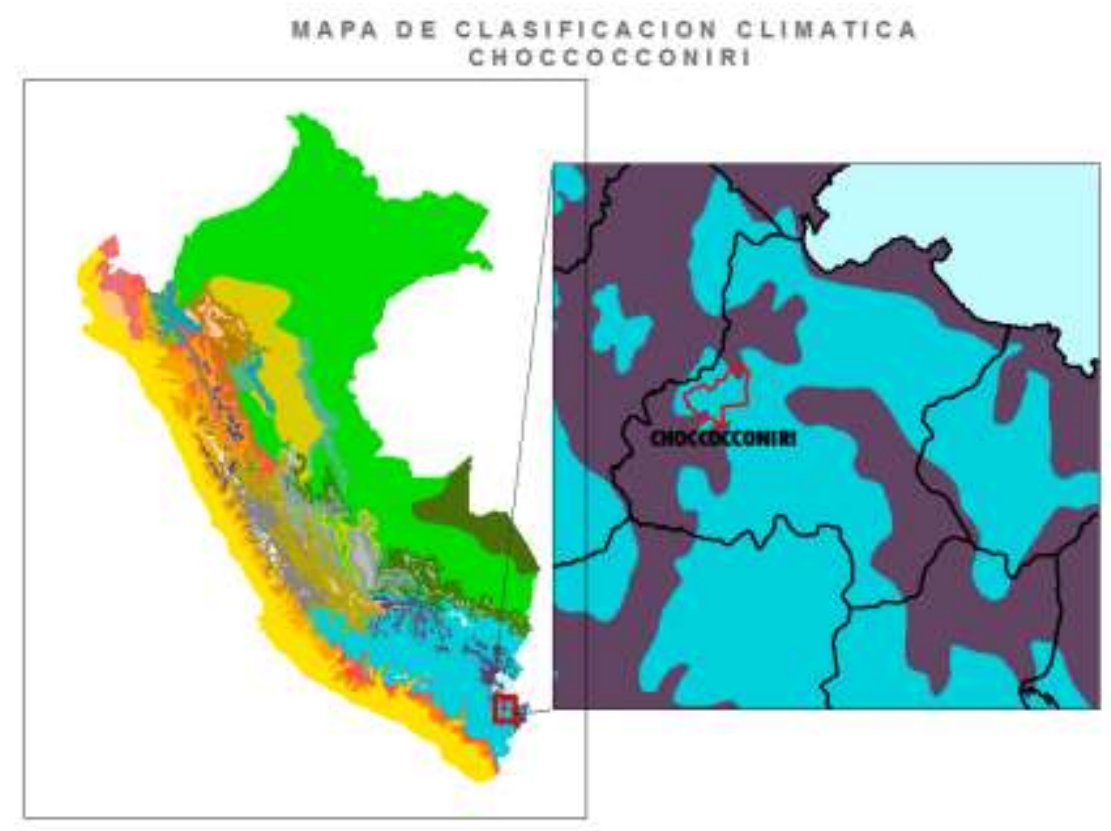

Figura 17. Mapa del clima de Choccocconiri Elaborado por: Madrigal G. (2017)

Datos más generales de la zona se muestra en la siguiente Tabla

Tabla 1

Descripción de las temperaturas y precipitaciones (máximas y mínimas), Juli - Puno

\begin{tabular}{lcc}
\hline Nombre & Puno & Juli \\
\hline Temperatura max. noviembre & $12.8^{\circ} \mathrm{C}$ & $15.5^{\circ} \mathrm{C}$ \\
Temperatura min. Julio & $5.9^{\circ} \mathrm{C}$ & $6.2^{\circ} \mathrm{C}$ \\
Precipitación máx. Junio & $3 \mathrm{~mm}$ & $5 \mathrm{~mm}$ \\
Precipitación min. Enero & $150 \mathrm{~mm}$ & $173 \mathrm{~mm}$ \\
\hline
\end{tabular}

Fuente: M Seluchi 1999.

Modificado por: Roman M. (2017)

\subsection{Relieve}

Para obtener el relieve y la altura se tuvo que trabajar mediante el programa Arcgis 10.2 a partir de un Modelo Digital de Elevación (MDE) generados de curvas de nivel, asi mismo, se utilizo imagenes del Dron Phanton 4Pro. 


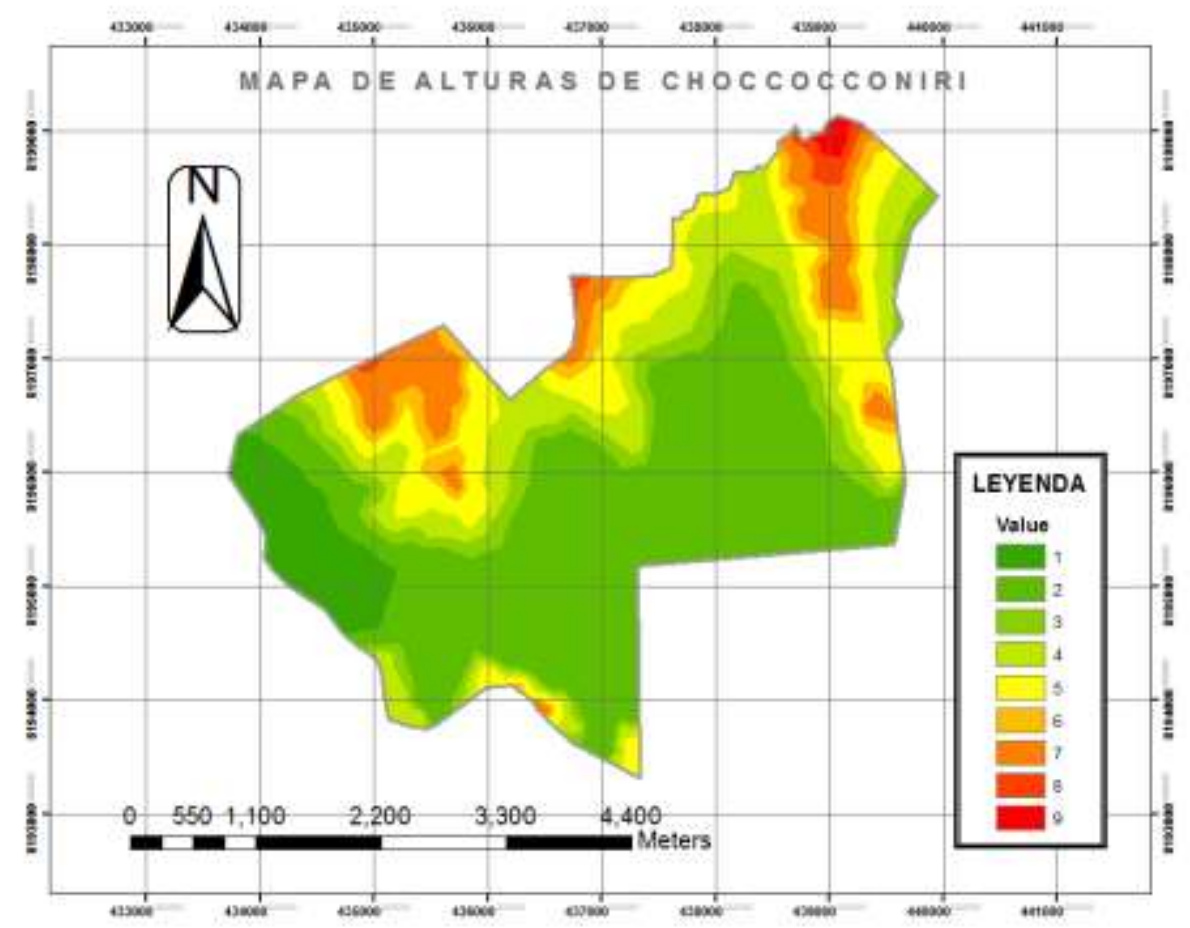

Figura 18. Mapa de altura de Choccocconiri

Elaborado por: Madrigal G. (2017)

La altura en Choccocconiri está comprendido entre los 3900 a 4200 msnm. Las alturas más elevadas, representadas por colores que van desde el amarillo a rojo se encuentran al Norte, y al Sur están las alturas más bajas (representadas por diferentes tipos de verde) formando llanuras (ver figura 19).

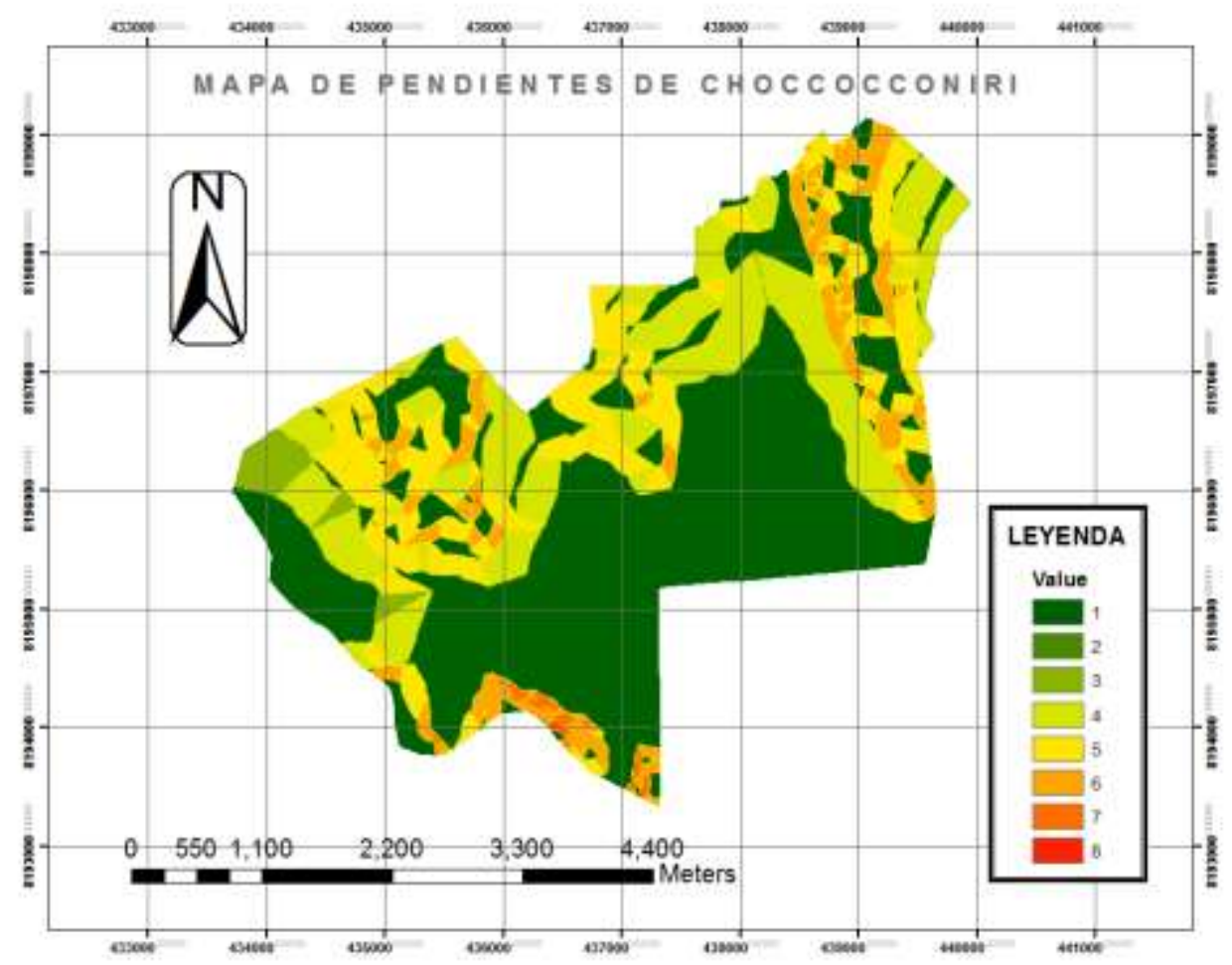

Figura 19. Mapa de pendientes de Choccocconiri Elaborado por: Madrigal G. (2017) 
En este caso para clasificar la pendiente se utilizará el siguiente cuadro de Gómez \& Garcia, (2016):

\begin{tabular}{clc}
\hline Clase & \multicolumn{1}{c}{ Descripción } & Pendiente $\mathbf{( \% )}$ \\
\hline $\mathbf{1}$ & Pendiente suave & 0 a 2 \\
$\mathbf{2}$ & Pendiente suave & 2 a 4 \\
$\mathbf{3}$ & Pendiente suave & 4 a 8 \\
$\mathbf{4}$ & pendiente moderada & 8 a 15 \\
$\mathbf{5}$ & pendiente moderada & $15-25$ \\
$\mathbf{6}$ & pendiente moderada & 25 a 50 \\
$\mathbf{7}$ & pendiente fuerte & 50 a 75 \\
$\mathbf{8}$ & pendiente fuerte & 75 a 100 \\
\hline
\end{tabular}

Se puede observar en la figura 19 que las pendientes más suaves de clase 1, 2, 3 y 4 (distintas tonalidades de verde) ocupan una gran superficie. Las pendientes de clase 5, 6, 7 y 8 de pendiente moderada a fuerte (que va de colores amarillo a rojo) ocupan una superficie no muy extensa, distribuyéndose en su mayoría en el Norte.

En la imagen tomada por el Dron se puede visualizar las Alturas y pendientes mas Fuertes, que estan enmarcadas en circulos de color rojo (figura 20)

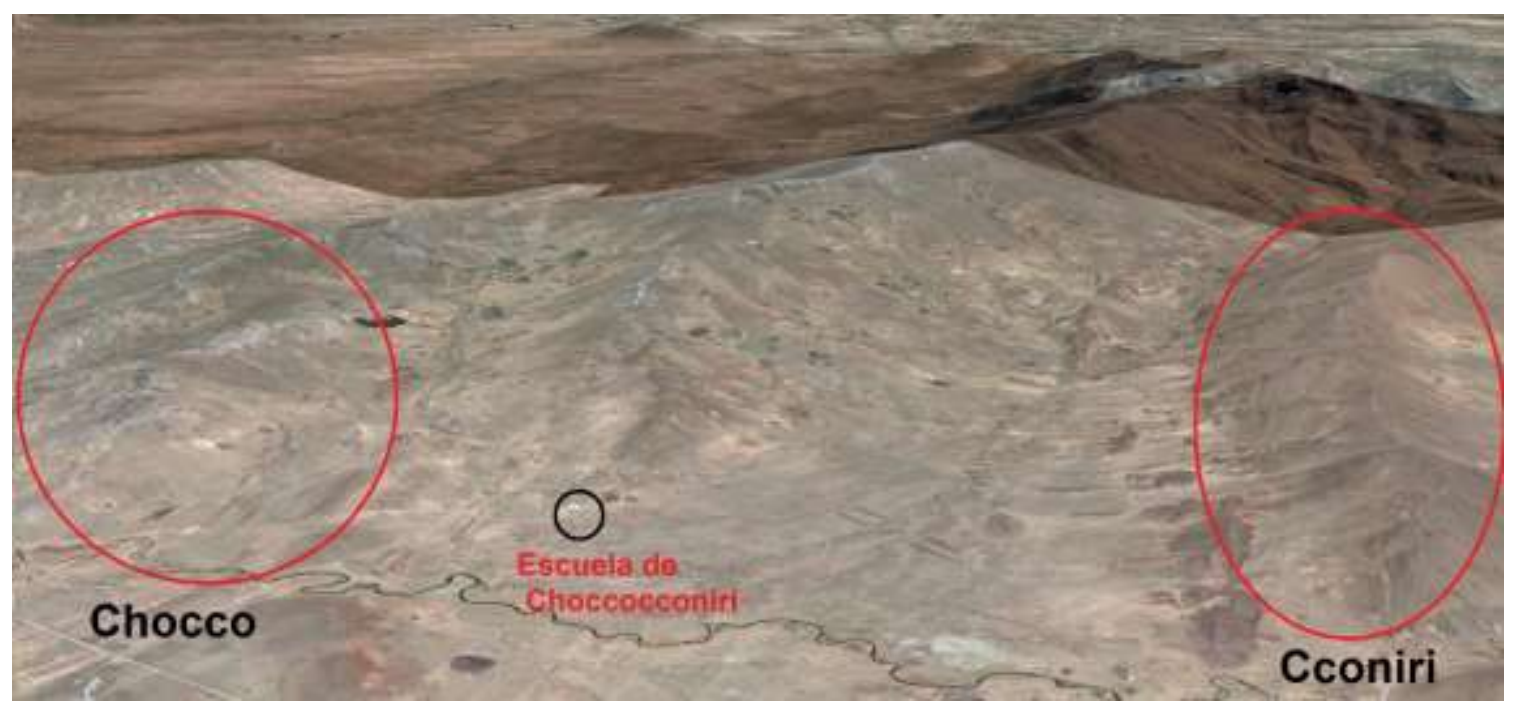

Figura 20. Vista panorámica de las principales áreas con elevación en la comunidad, Google Earth Pro Elaborado por: Roman M. (2017)

\subsubsection{Discusion de resultados}

Los resultados de este trabajo han permitido demostrar las distintas especies vegetales predominantes en la comunidad de Choccocconiri, además de la relación estrecha que existe entre la vegetación, el clima y el relieve (pendiente y altitud).

La comunidad de Choccocconiri es un lugar rico en especies vegetales endémicas de esa zona, Se registraron un aproximado de 70 especies vegetales entre líquenes, musgos, algas, gramíneas, solo una 
especie de árbol y un hongo en tiempo de reproducción esta diversidad endémica se relacionan principalmente con 3 causas: altitud, relieve y clima.

El mapa de Cobertura vegetal y el Índice de Vegetación de Diferencia Normaliza (NDVI) (Figura 14 y figura 15) son un buen indicador de la cubierta vegetal predominante en la zona, pues brindan datos complementarios a los recopilados en campo. Esto es así porque el mapa de cobertura vegetal muestra que la formación vegetal característica de Choccocconiri es el denominado pajonal andino que son hierbas en forma de manojo de hasta $80 \mathrm{~cm}$ de alto (MINAM, 2015). En lo que respecta al NDVI según Manrique, (1999) es un buen indicador del vigor de la vegetación o por el contrario su débil vitalidad, es decir, mientras más verde y más presencia de vegetación haya en una zona el valor del NDVI se acercara a 1 o por el contrario, si la vegetación es pobre o el suelo es desnudo el valor del NDVI disminuirá hasta -1. El valor medio del NDVI en el área de estudio es de 0.14 , esto quiere decir que el nivel de vigor y verdor de la vegetación es bajo, confirmando la presencia de pajonales, matorrales y pastos secos, es más, Meneses-Tovar, (2011) menciona que las comunidades vegetales con los valores del NDVI cercanos a 0.1 representan áreas en los cuales las hojas son muy escasas, con presencia de pastizales y zonas de matorral.

Por lo que se refiere a la altura y la pendiente, estos son buenos indicadores de la vegetación, pues estos están muy relacionados. Galan de Mera, Rosa, \& Cáceres, (2002), mencionan que los pajonales, pajonal-tolares y cespedes de la puna se encuentran entre los 3600-5100 msnm, y constituyen en muchos lugares la vegetacion climax, ademas este tipo de vegetacion se encuentran en pendientes suaves a moderadas tal como ocurre en Choccocconiri.

El clima (lluvioso semifrigido (de Tundra) y frio Boreal (de los valles Mesoandinos)), que en Choccocconiri es en extremo rudo por las bajas temperaturas cuyo valor promedio es de $7^{\circ} \mathrm{C}$ y precipitaciones medias de $700 \mathrm{~mm}$, solo se mencionan estos dos parámetros porque tal como afirma Weberbauer, (1944) son los principales factores que intervienen en la distribución de la vegetación. La vegetación que puede vivir en estas condiciones climáticas, en verdad rudas, son los pajonales, tolares, bosques de keuña, rodales de ccara y formaciones de plantas almohadillas (Brack \& Mendiola, 2000).

Por todo esto, podemos afirmar que la vegetación en la Comunidad de Choccocconiri está estrechamente relacionado a las condiciones climáticas (temperatura y precipitación principalmente), a la altitud y relieve. Estos parámetros condicionan el tipo de vegetación existente.

\section{Conclusiones}

- La vegetación identificada en campo muestra la biodiversidad que hay en la comundad de Choccocconiri, muchas de ellas son bioindicadores y gran parte útiles en la medicina tradicional. La vegetación predominante en la zona de estudio, según el mapa de cobertura vegetal es pajonal andino, bofedal y agricultura andina, esta última considerara una unidad antrópica de cobertura vegetal. 
- Tras el tratamiento en el programa Arcgis 10.2 de las imágenes multiespectrales del satélite Landsat 8 se obtuvo el Índice de Vegetación de Diferencia Normalizada (NDVI) el cual nos dio un valor medio de 0.14 esto quiere decir que el área de estudio está conformada en su mayoría por plantas de hojas muy escasas, con presencia de pastizales y zonas de matorral, esto fue observado en campo siendo la mayor parte de especies gramíneas que cubren extensas zonas.

- El clima en Choccocconiri es lluvioso semifrigido (de Tundra), este clima se caracteriza por presentar precipitaciones anuales en promedio de $700 \mathrm{~mm}$, temperaturas medias anuales de $7^{\circ} \mathrm{C} \mathrm{y}$ nieves perpetuas en alta montaña. También presenta un clima frio Boreal (de los valles Mesoandinos), con características similares al clima lluvioso semifrígido

- La altitud está comprendida entre los 3900 a 4200 msnm con un relieve suave a moderado en la mayor parte del área de estudio y fuerte en áreas pequeñas que se encuentran al norte.

- La vegetación está estrechamente relacionada al clima, la altitud y relieve.

- Estos elementos encontrados dan soporte para tener una valoración positiva del geopaisaje de Choccocconiri.

\section{Recomendaciones}

Se recomienda, hacer un estudio específico de un representante de cada especie para conocer el comportamiento de este en su entorno con más precisión. También realizar una visita en temporada diferente a Julio esperando se encuentren diferentes especies u otras en estado de floración.

Los elementos hallados y la valoración positiva de estos ameritan una propuesta de geoparque.

\section{Agradecimiento}

Se agradece al Centro de Recursos en Geociencia, en especial al director Orlando Poma por la conducción en la elaboración del presente artículo de investigación, también de manera especial a la comunidad de Choccocconiri resaltando su hospitalidad y apoyo en los días de trabajo en campo, también la traducción y guía de la Señora Lourdes Elias.

\section{Referencias}

Aguilar, N., Galindo, G., Fortanelli, J., \& Contreras, C. (2010). Indice Normalizado de vegetacion en caña de azucar en la huasteca Potosina. Avances en Investigacion Agropecuaria, 49-65.

Brack, A., \& Mendiola, C. (2000). Ecologia del Peru. Lima: Editorial Bruño.

Galán de Mera, A., Cáceres, C., \& Gonzales, A. (2003). La vegetacion de la alta montaña andina del Sur del Peru. Acta Botanica Malacitana, 121-147.

Galan de Mera, A., Rosa, V., \& Cáceres, C. (2002). una aproximacion sintaxonomica sobre la vegetacion del Peru. Clases, oredenes y alianzas. Acta Botanica Malacitana, 75-103.

Gavilán, R. (1994). Estudio de las relaciones entre la vegetacion y el clima en el sistema central español. Madrid: Universidad Complutense de Madrid. 
Gómez, I., \& Garcia, A. (2016). Reclasificar pendientes. Venezuela: Educacion Ambiental sin Fronteras.

Hort, A. (1916). Enquiry into plants and minor works on odours and weather signs. By Theophrastus. Londres: W. Heinemann.

Hutchinson, J., Jacquin, A., Hutchinson, S., \& Verbesselt, J. (2015). Monitoring vegetation change and dynamics on US Army training lands using satellite image time series analysis. Journal of environmental management, 355-366.

Manrique, E. (1999). Indice de vegetacion. Aplicacion el NDVI. TELEDETECCION. Avances y Aplicaciones, 217219.

Meneses-Tovar, C. (2011). El indice normalizado diferencial de la vegetacion como indicador de la degradacion del bosque. Mexico: Unasylva.

Millano, J., \& Paredes, F. (2017). Variabilidad de la vegetacion con el indice de diferencia normalizada (NDVI). Novum Scientiarum, 33-44.

MINAM. (2015). Mapa Nacional de Cobertura Vegetal - Memoria Descriptiva. Lima: Ministerio del Ambiente, Direccion General de Evaluacion, Valoracion y Financiamiento del Patrimonio Natural.

Rodriguez, N., Pabón, J., Bernal, N., \& Martínez, J. (2010). Cambio climatico y su relacion con el uso del suelo en los Andes Colombianos. Bogota: Instituto de Investigacion de Recursos Biologicos Alexander von Humboldt, Universidad Nacional de Colombia.

SENAMHI. (s.f.). Mapa Climatico Nacional. Recuperado el 11 de Agosto de 2017, de http://www.senamhi.gob.pe/?p=mapa-climatico-del-peru

Weberbauer, A. (1944). Clima y Vegetacion en los Andes del Peru y en su Territorio Costanero. Academia de Ciencias Exactas.

Lijteroff, R., Lima, L., \& Prieri, B. (2009). Uso de liquenes como bioindicadores de contaminación atmosférica en la ciudad de San Luis Argentina. Revista Internacional de Contaminación Ambiental, 25(2), 111-120. Retrieved from http://www.scielo.org.mx/pdf/rica/v25n2/v25n2a6.pdf

Vázquez, A. J., \& Arregui, L. (2006). Helchos amenazados de Andalucía, 65. Retrieved from https://www.juntadeandalucia.es/medioambiente/web/Bloques_Tematicos/Publicaciones_Divulgacion _Y_Noticias/Documentos_Tecnicos/helechos_amenazados/libro_helechos.pdf 